\title{
A Case of Anterior Hypopituitarism Showing Recurrent Pituitary Mass Associated with Central Diabetes Insipidus
}

\author{
KANAE NISHIMURA, TOSHIHIRO TAKAO, TOMOKO MIMOTO, AKINORI MATSUMORI, \\ ATSUSHI SASAOKA AND KOZO HASHIMOTO \\ Department of Endocrinology, Metabolism and Nephrology, Kochi Medical School, Nankoku 783-8505, Japan
}

\begin{abstract}
We report a case of anterior hypopituitarism showing recurrent pituitary mass associated with central diabetes insipidus. A 76-year old woman was hospitalized with general fatigue and $5 \mathrm{~kg}$ body weight loss. Endocrinological examinations and pituitary provocative tests demonstrated hypopituitarism and central diabetes insipidus. T1-weighted image of magnetic resonance imaging (MRI) revealed an intrasellar cystic mass with ring enhancement suggesting pituitary abscess. MRI films subsequently obtained from another hospital and studied retrospectively showed intrasellar cystic mass with ring enhancement 4 years earlier, and a mass shape that was decreased after 2 years. Over the subsequent years, the patient has remained asymptomatic with hormone replacement therapy only. Cystic pituitary adenoma or Rathke's cleft cyst with repeated infection may be involved in the repeated change of pituitary mass shape although neither pituitary surgery nor a pituitary biopsy was performed because of the patient's age and condition. It is reported that apparent recurrence of Rathke's cleft cysts after initially successful surgery was higher than suggested by previous reports, and that long-term follow-up with pituitary imaging and neuroophthalmological assessment is essential. Careful evaluation by follow-up brain MRI is needed in the present case to prevent future recurrence of pituitary abscess.
\end{abstract}

Key words: Hypopituitarism, Magnetic resonance imaging (MRI), Pituitary abscess

(Endocrine Journal 50: 825-829, 2003)

PITUITARY abscess is a relatively rare disease in the pituitary mass and is difficult to make differential diagnosis with other cystic diseases preoperatively [1-4]. The routes of infection to the pituitary are: 1) blood borne, 2) direct expansion from contiguous structure or from intrasellar tumor, 3) postoperative. Blood borne infection with sepsis has often been reported when dealing with no antibiotics; however, cases of unknown etiology are most common recently $[5,6]$. We report a case of anterior hypopituitarism showing recurrent pituitary mass associated with central diabetes insipidus. In addition, this report presents recurrent pituitary mass by a review of the literature.

Received: April 14, 2003

Accepted: August 28, 2003

Correspondence to: Kanae NISHIMURA, M.D., Department of Endocrinology, Metabolism and Nephrology, Kochi Medical School, Kohasu, Okoh-cho, Nankoku 783-8505, Japan

\section{Case Report}

A 76-year old woman with thirst, polyuria and general fatigue was diagnosed as central diabetes insipidus by endocrinological examinations in 1995 . Pituitary tumor, adrenal insufficiency and hypothyroidism were also found, and hydrocortisone, levothyroxine sodium, and DDAVP had been administered. Follow-up magnetic resonance imaging (MRI) was performed repeatedly. After hydrocortisone replacement was terminated by her former hospital in May 2000, she visited another hospital with general fatigue and $5 \mathrm{~kg}$ body weight loss in June 2000. Hydrocortisone replacement was restarted after the termination of levothyroxine sodium replacement; at that time, she was transferred to our hospital. The patient had no headache, visual disturbance, meningial signs or inflammatory signs.

On physical examination, her height was $156 \mathrm{~cm}$ and her body weight was $45.7 \mathrm{~kg}$. Her blood pressure was $120 / 65 \mathrm{mmHg}$ and pulse rate was a regular $58 /$ 
min. Visual field and acuity were normal. Goiter was not palpable. Systolic murmur (Levine II/VI) was audible. Lung and abdomen were normal. Neurological examinations revealed no other abnormalities.

Hematological data showed anemia (hemoglobin: $9.1 \mathrm{~g} / \mathrm{dl}$ ). White blood cell count was $5100 / \mu 1$. Creactive protein was negative. Serum transanimoferase levels were slightly elevated (AST: 81, ALT: $41 \mathrm{IU} / 1$ ). Blood urea nitrogen and creatinine levels were 21 and $0.7 \mathrm{mg} / \mathrm{dl}$, respectively. Plasma glucose level was $67 \mathrm{mg} / \mathrm{dl}$. Serum electrolyte levels were within normal limit (Na: 143, K: 3.8, Cl: $106 \mathrm{mEq} / \mathrm{l})$. Osmotic pressure of blood $(287 \mathrm{mOsm} / \mathrm{kg})$ and urine $(515 \mathrm{mOsm} /$ $\mathrm{kg}$ ) were within normal limit as DDAVP was given $(10 \mu \mathrm{g} /$ day $)$. Tuberculin test was negative. Plasma adrenocorticotropic hormone (ACTH) and thyroid stimulating hormone (TSH) levels were $15.4 \mathrm{pg} / \mathrm{ml}$ (normal range 7-56) and $0.04 \mu \mathrm{IU} / \mathrm{ml}(0.27-4.2)$, respectively, as only hydrocortisone $(10 \mathrm{mg})$ per day but not thyroid hormone were given by her former hospital. Serum prolactin (PRL) levels were $33.1 \mathrm{ng} / \mathrm{ml}$ (0.1-26). Serum luteinizing hormone (LH), follicle stimulating hormone (FSH), free triiodothyronine $\left(\mathrm{T}_{3}\right)$, free thyroxine $\left(\mathrm{T}_{4}\right)$ and cortisol levels were $<0.25$ $\mathrm{mIU} / \mathrm{ml}(0.9-15.5), 2.0 \mathrm{mIU} / \mathrm{ml}(3.1-23.9), 1.0 \mathrm{pg} / \mathrm{ml}$ (2.6-5.1), $0.59 \mathrm{ng} / \mathrm{dl}(1.0-1.8), 2.19 \mu \mathrm{g} / \mathrm{dl}$ (4.6-24.5), respectively. Aldosterone, urinary 17-OHCS and 17KS levels were $<10 \mathrm{pg} / \mathrm{ml}$ (36-240), $3.6 \mathrm{mg} /$ day (2.2$7.3)$ and $1.8 \mathrm{mg} / \mathrm{mg}(2.4-11.0)$, respectively, suggesting adrenal insufficiency. Both anti-thyroid peroxidase (anti-TPO) antibody and anti-thyroglobulin antibody levels were negative.

Pituitary provocative tests were performed as follows (Table 1): A combined bolus injection of $500 \mu \mathrm{g}$ of thyrotropin-releasing hormone (TRH), $100 \mu \mathrm{g}$ of luteinizing hormone-releasing hormone (LH-RH), 100 $\mu \mathrm{g}$ of growth hormone releasing-hormone $(\mathrm{GRH})$ and

Table 1. A combined $(100 \mathrm{mgCRH}+100 \mathrm{mgGRH}+500 \mathrm{mg}$ $\mathrm{TRH}+100 \mathrm{mgLHRH}$ ) anterior pituitary function test

\begin{tabular}{lccccc}
\hline & 0 & 15 & 30 & 60 & $90(\mathrm{~min})$ \\
\hline ACTH $(\mathrm{pg} / \mathrm{ml})$ & 9.96 & 73.3 & 87.5 & 92.8 & 95.1 \\
TSH $(\mu \mathrm{IU} / \mathrm{ml})$ & 0.12 & 0.26 & 0.34 & 0.38 & 0.33 \\
PRL $(\mathrm{ng} / \mathrm{ml})$ & 39.1 & 60.8 & 71.6 & 69.7 & 66.2 \\
GH $(\mathrm{ng} / \mathrm{ml})$ & 0.88 & 5.54 & 11.6 & 19.5 & 18.0 \\
LH $(\mathrm{mIU} / \mathrm{ml})$ & 0.30 & 0.38 & 0.60 & 0.67 & 0.70 \\
FSH $(\mathrm{mIU} / \mathrm{ml})$ & 2.02 & 2.29 & 2.74 & 3.22 & 3.79 \\
Cortisol $(\mu \mathrm{g} / \mathrm{dl})$ & 1.20 & 1.79 & 3.14 & 3.94 & 3.44 \\
\hline
\end{tabular}

$100 \mu \mathrm{g}$ of corticotropin-releasing hormone (CRH) was performed and multiple blood samples were collected to measure hormone concentrations before and 30, 60 and $90 \mathrm{~min}$ after injection. PRL showed normal response to TRH. GH showed a delayed but good response to GRH. A prolonged ACTH response to $\mathrm{CRH}$ was seen, while no cortisol response was observed. The response of LH and FSH to LH-RH and TSH to TRH showed no response, suggesting partial hypopituitarism as well as possible hypothalamic insufficiency. Insulin tolerance test and continuous LH-RH test were not performed because of her age and condition. As no cortisol response to $\mathrm{CRH}$ was seen, rapid ACTH test $(250 \mu \mathrm{g})$ was performed. Both cortisol and aldosterone showed no response to exogenous ACTH, suggesting possible primary adrenal insufficiency as well as hypopituitarism and hypothalamic insufficiency although ACTH-Z test was not performed because of the patient's refusal.

T1-weighted image of magnetic resonance imaging (MRI) revealed an intrasellar cystic mass with ring enhancement (Fig. 1, Panel E). High intensity signal in the posterior lobe of the pituitary was not seen at this point. The patient was treated conservatively, without surgery, using hydrocortisone $(10 \mathrm{mg} /$ day $)$ and levothyroxine sodium $(25 \mu \mathrm{g} /$ day $)$ as replacement therapy. The pituitary mass decreased spontaneously after 6 months (Panel F). MRI films subsequently obtained from another hospital and studied retrospectively showed intrasellar cystic mass with ring enhancement 4 years earlier and that the mass shape was decreased after 2 years (Panel A-C). In addition, an inflammatory granuloma, possibly caused by an abscess was found in the posterior part of pituitary (Panel D). Taken together with endocrinological examinations and MRI findings, pituitary abscess is most possible for the present case although neither pituitary surgery nor a pituitary biopsy was performed because of the patient's age and condition.

Over the subsequent years, the patient has remained asymptomatic only with hormone replacement therapy.

\section{Discussion}

Since the first case of pituitary abscess was reported in 1912, only 121 cases have been described [1]. Previous reports demonstrated that the ratio of pituitary abscess in the sellar mass was $0.6 \%$ [7] and $0.48 \%$ [1]. 

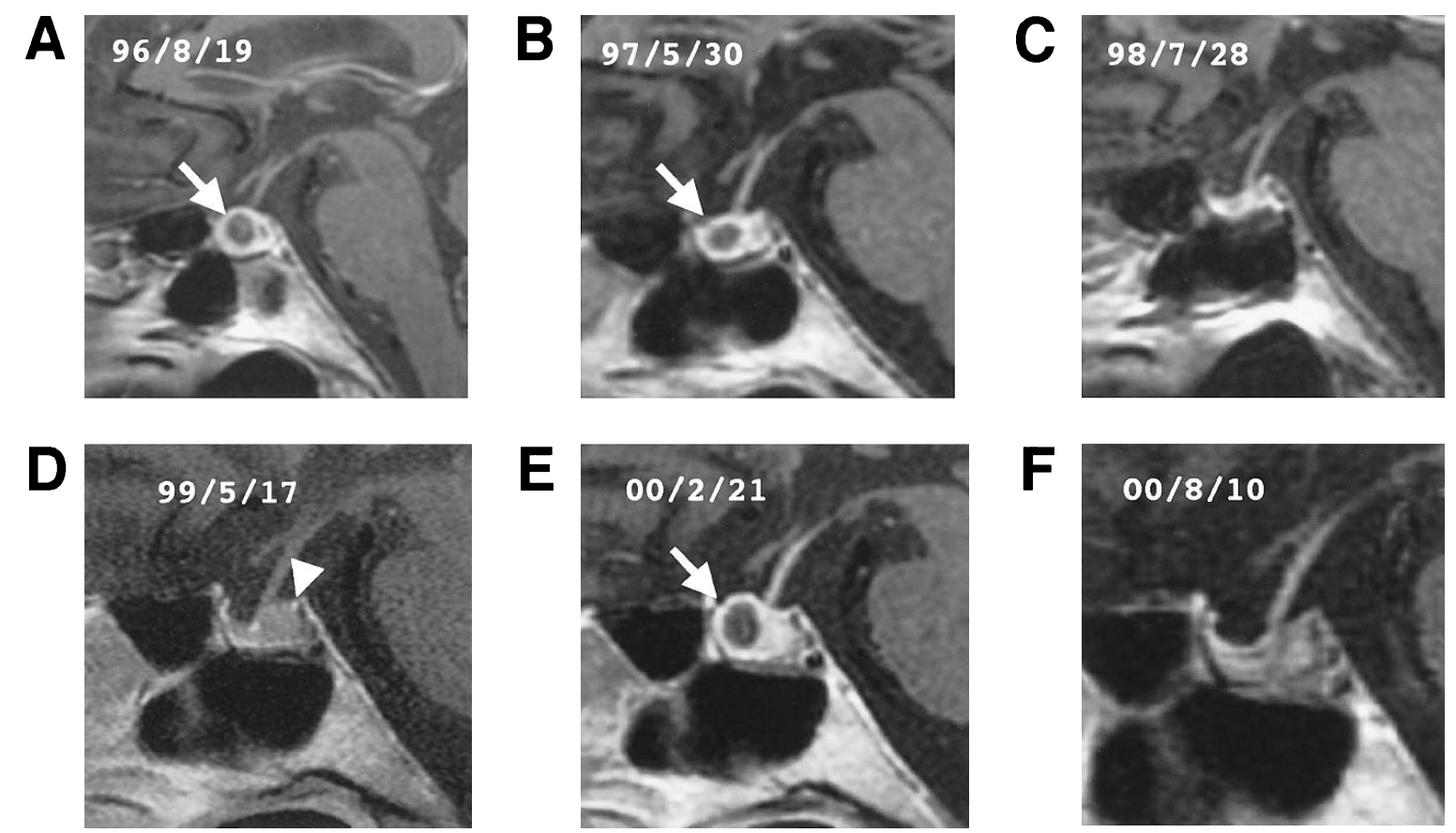

Fig. 1. Pituitary mass examined by MRI from 1996 to 2000.

Panel A (1996/8/19): Pituitary mass (arrow), possibly anterior lobe, with ring enhancement exists inside sella and also extends to upper side. Ring enhancement shows thickening of the wall.

Panel B (1997/5/30): Mass (arrow) volume is decreased compared with figure A.

Panel C (1998/7/28): Mass is diminished and the pituitary shape became flat.

Panel D (1999/5/17): Mass is still unremarkable. Another solid mass (arrowhead) with homogenous enhancement is seen in the posterior side in sella.

Panel E (2000/2/21): Pituitary mass with ring enhancement (arrow). Mass shows thickening of the wall. Shape of the solid mass on the posterior side was not changed.

Panel F (2000/8/10): Disappearance of pituitary mass with ring enhancement and absence of inside signal.

Clinical symptoms of pituitary abscess were reported as hypopituitarism $(70.2 \%)$, visual disturbance $(51.1 \%)$, meningitis $(42.1 \%)$ and diabetes insipidus $(42.1 \%)$ $[3,5]$. It was reported that endocrinological examinations in pituitary abscess or Rathke's cleft cyst showed an elevated PRL concentrations, and disturbed other pituitary hormone levels because the inflammation spread to the pituitary stalk and the hypothalamus, and decreased PRL inhibiting factors $[4,8]$. The symptoms of anterior pituitary deficiency were particularly seen in pituitary abscess in anterior lobe [4]. It was reported that $42.1 \%$ of pituitary abscess showed diabetes insipidus and that was more frequent than pituitary adenoma with diabetes insipidus [9]. These results showed the widely expanded inflammation from pituitary abscess which affected severe pituitary dysfunction [3].

In the present case the response of LH and FSH to LH-RH and TSH to TRH showed partial hypopitui- tarism. In addition, delayed ACTH and GH response and elevated PRL suggested hypothalamic insufficiency although insulin tolerance test and continuous LH-RH test were not performed because of her age and condition. The inflammation of pituitary abscess extended to pituitary stalk and/or hypothalamus possibly caused subsequent central diabetes insipidus.

The present case showed no inflammatory or meningeal signs. The cases without inflammatory or meningeal signs are reported to be $30-42 \%[5,6]$. Inflammatory signs in the laboratory data are rarely seen in this disease, making it difficult to arrive at a differential diagnosis with other cystic diseases preoperatively [2] as one-third of pituitary abscess are reported to originate from infectious pituitary tumor, craniopharingioma and Rathke's cleft cyst [2, 3, 10-14].

Radiological examinations show the enlargement of sella turcica by X-ray and CT shows nonspecific findings such as low density area with ring enhancement. 
T1-weighted image of MRI mostly reveals an intrasellar cystic mass with ring enhancement [6, 7, 15-19]. The mechanisms involved in the repeated change of pituitary mass shape in the present case are unknown. The pathological basis of the ring enhancement might be that the cyst wall was lined by granulation tissue which consists of numerous small vessels and capillaries [20]. This is the non-specific inflammatory reaction against bacterial infection. Therefore, cystic pituitary adenoma or Rathke's cleft cyst with repeated infection may be involved in the change of pituitary mass shape. Mukherjee et al. reported the cases with the recurrence of Rathke's cleft cyst [21], supporting the possibility of repeated pituitary abscess based on Rathke's cleft cyst.

The management recommended for pituitary abscess is surgical drainage and antibiotic treatment [1012]. In contrast, the improvement of pituitary abscess without operation was also reported [22]. It is reported that apparent recurrence of Rathke's cleft cysts after initially successful surgery was higher than suggested by previous report, and that long-term follow-up with pituitary imaging and neuroophthalmological assessment is essential [21]. In the present case, neither pituitary surgery nor a pituitary biopsy was performed because of the patient's age and condition. Careful evaluation by follow-up brain MRI is needed in the present case to prevent recurrence of pituitary abscess.

\section{Acknowledgments}

We are most grateful to Dr. Ichiro Fujisawa (Kishiwada City Hospital, Kishiwada, Japan) for comments and suggestions on the characterization of MRI findings.

\section{Reference}

1. Vate GE, Berger MS, and Wilson CB (2001) Diagnosis and management of pituitary abscess: a review of twenty-four cases. J Neurosurg 95: 233-241.

2. Ikeda M, Tamaki N, Kondoh T, Ehara K, Nagashima T, and Ohta K (2001) Pituitary abscess: Report of Six Cases. Jpn J Neurosurg (Tokyo) 10: 454-460.

3. Sato M, Matsushima Y, Taguchi J, et al. (1995) A case of pituitary abscess caused by infection of Rathke's cleft cyst. No Shinkei Geka 23: 991-995.

4. Osaka Y, Horikawa Y, Nakahara Y, Sakakibara T, Yoshino E (2001) Three cases of Pituitary Abscess. No Shinkei Geka 29: 741-745.

5. Uede T, Daibo M, Ohotaki M, Morimoto S, Tanabe S, Hashi K (1986) Pituitary abscess: report of two cases and a review. No Shinkei Geka 14: 1383-1388.

6. Sugimoto S, Kondo H, Yamada H (1996) Primary pituitary abscess: a case report. No Shinkei Geka 24: 343-346.

7. Jain KC, Varma A, Mahapatra AK (1997) Pituitary abscess: A series of six cases. Br J Neurosurg 11: 139143.

8. Gotoh M, Nakano J, Midorikawa S, Niimura S, Ono Y, Mizuno K (2002) Multiple endocrine disorders and Rathke's cleft cyst with klinefelter's syndrome: A case report. Endocrine J 49: 523-529.

9. Blackett PR, Bailey JD, Hoffman HJ (1980) A pituitary abscess simulating an intrasellar tumor. Surg Neurol 14: 129-131.

10. Jadhav RN, Dahiwadkar HV, Palande DA (1998) Abscess formation in pituitary adenoma. Case report.
Neurosurgery 43: 616-619.

11. Guigui J, Boukobza M, Tamer I, Guichard JP, Wyplosz B, Reizine D, Merland JJ (1998) Case report: MRI and CT in a case of pituitary abscess. Clin Radiol 53: 777779.

12. Shanley DJ, Holmes SM (1994) Salmonella typhi abscess in craniopharyngioma: CT and MRI. Neuroradiology 36: 35-36.

13. Thomas N, Wittert GA, Scott G, Reilly PL (1998) Infection of a Rathke's cleft cyst: A rare cause of pituitary abscess. J Neurosurg 89: 682.

14. Israel ZH, Yacoub M, Gomori JM, Dotan S, Fellig Y, Shoshan Y, Spektor S (2000) Rathke's cleft cyst abscess: Case report. Pediatr Neurosurg 33: 159-161.

15. Martines F, Scarano P, Chiappetta F, Gigli R (1996) Pituitary abscess. A case report and review of the literature. J Neurosurg Sci 40: 135-138.

16. Ahmed YS, Bradey N, Halaka AN, Belchetz PE, Ironside JW (1989) Primary pituitary abscess: Surgical management and endocrine assessment in three cases. Br J Neurosurg 3: 409-414.

17. Takahashi T, Shibata S, Ito K, Ito S, Tanaka M, Suzuki S (1996) Neuroimaging appearance of pituitary abscess complicated with close inflammatory lesions: Case report. Neurol Med Chir (Tokyo) 38: 51-54.

18. Hwang SL, Howng SL (1996) Pituitary abscess: CT and MRI findings. J Formos Med Assoc 95: 267-269.

19. Walansky LJ, Gallagher JD, Heary RF, Malantic GP, Dasmahapatra A, Shaderowfsky PD, Budhwani N (1997) MRI of pituitary abscess: two cases and review 
of the literature. Neuroradiology 39: 499-503.

20. Bognar L, Szeifert GT, Fedorcsak I, Pasztor E (1992) Abscess formation in Rathke's cleft cyst. Acta Neurochir (Wien) 117: 70-72.

21. Mukherjee JJ, Islam N, Kaltsas G, Lowe DG, Charlesworth M, Afshar F, Trainer PJ, Monson JP, Besser GM, Grossman AB (1997) Clinical, radiological and pathological features of patients with Rathke's cleft cysts: Tumors that may recur. J Clin Endocrinol Metab 82: $2357-2362$.

22. Dechambenoit G, Datie A, Grunitzky EK, Ba Zeze V, Boni N, Kakou M, Santini JJ (1993) Pituitary abscess treated by medication. Rev Neurol (Paris) 149: 567571. 